\title{
Clinical Profiles and Outcomes of the Most Common Inherited Metabolic Diseases in the Philippines: A Review of the National Institutes of Health - Institute of Human Genetics Metabolic Registry
}

\author{
Monette R. Faner ${ }^{1}$ and Mary Anne D. Chiong ${ }^{1,2}$ \\ ${ }^{1}$ Section of Clinical Genetics, Department of Pediatrics, College of Medicine and Philippine General Hospital, University of the Philippines Manila \\ ${ }^{2}$ Institute of Human Genetics, National Institutes of Health, University of the Philippines Manila
}

\begin{abstract}
Objective. This study reviewed the profiles and outcomes of patients diagnosed to have the five most common inherited metabolic diseases (IMDs) in the Metabolic Registry of the National Institutes of Health - Institute of Human Genetics (NIH-IHG) from 1999 to 2016.

Methods. The medical records of the patients diagnosed with the following inherited metabolic diseases were reviewed: maple syrup urine disease (MSUD), galactosemia, hyperphenylalaninemias (including classical phenylketonuria, mild hyperphenylalaninemia, and pterin defects), mucopolysaccharidoses (MPS), and adrenoleukodystrophy (ALD).
\end{abstract}

Results. There was a total of 567 patients with IMDs, giving a minimum estimated burden of 1.9 per 100,000 livebirths (1:51,760). Clinical presentations were similar to those reported in literature. Majority of the cases of galactosemia and hyperphenylalaninemias presented with a positive newborn screening result. The local prevalence of MSUD and MPS II were higher compared to international data, which may be explained by reported founder mutations among Filipinos. Majority of the patients with IMDs were diagnosed late leading to preventable developmental delay or intellectual disability and death. Majority of patients with MSUD (80.6\%) and MPS (94.7\%) had intellectual disability or developmental delay. Mortality was $50.5 \%$ among patients with MSUD and $100 \%$ among patients with adrenoleukodystrophy.

Conclusion. There is a diversity of IMDs present in the country. A long-term strategic plan, such as the full implementation of the National Rare Disease Act, is foreseen to improve access to comprehensive healthcare and quality of life of patients with IMDs in the country.

Key Words: inherited metabolic diseases, inborn errors of metabolism, maple syrup urine disease, galactosemia, hyperphenylalaninemia, mucopolysaccharidoses, adrenoleukodystrophy, rare disease law

\section{INTRODUCTION}

Active Poster Presentation in the Asian Society of Pediatric Research, October 2-4, 2018, Manila, and Poster Presentation in the Asia Pacific Conference on Human Genetics, November 7-9, 2019, Manila.

Corresponding author: Monette R. Faner, MD

Department of Pediatrics

Philippine General Hospital

University of the Philippines Manila

Taft Avenue, Manila 1000, Philippines

Email: mrfaner@up.edu.ph
Inherited metabolic diseases (IMDs) or inborn errors of metabolism (IEMs) are a diverse class of genetic disorders manifesting as disruption of cellular biochemical functions. At present, there are at least 600 different IMDs described and new disorders are continuously being identified. ${ }^{1}$ Clinical presentations, severity, management, and outcomes are variable, and can virtually involve any organ or system. IMDs are present in every country but are perceived to be very rare because they were not recognized and not documented especially in many Asian countries. ${ }^{2}$ Several studies have shown a prevalence of 1 in 800-5,000 for IMDs. ${ }^{1}$ However, the local 
Inherited Metabolic Diseases in the Philippines

prevalence is unknown. Early detection through clinical recognition and appropriate testing will aid in giving optimum management for the patients and counseling for the families.

At present, there is no national system implemented for the registry of rare diseases. The Institute of Human Genetics (IHG) of the National Institutes of Health (NIH) in the University of the Philippines Manila (UPM), established in 1999, pioneered the genetics services in the country and the Biochemical Genetics Unit serves as the reference laboratory for the national expanded newborn screening program for the confirmatory testing of amino acid, organic acid, and fatty acid oxidation disorders. ${ }^{3}$ It has kept a local registry of patients diagnosed with IMDs referred from the patients seen in the Philippine General Hospital, private clinics of geneticists, and the Newborn Screening Reference Center.

This paper aimed to review the profiles and outcomes of patients diagnosed to have inherited metabolic diseases included in the Metabolic Registry of the National Institutes of Health - Institute of Human Genetics from 1999 to 2016. The data from this study could aid the government and non-government agencies, organizations, and institutions in the planning of comprehensive programs for patients with rare diseases such as IMDs in the country.

\section{MATERIALS AND METHODS}

Medical records of patients listed in the NIH-IHG metabolic registry diagnosed to have the 5 most common IMDs from 1999 to December 2016 were reviewed. Less common inherited metabolic diseases were not discussed in this study. Data on the last reported status of the patients diagnosed with inherited metabolic diseases (presence of intellectual disability, alive/dead, causes of mortality) were based on the latest update indicated in the available medical records.

The study was reviewed and approved by the University of the Philippines Manila Research Ethics Board (UPMREB 2017-261-01). In-patient and outpatient charts of the patients were obtained from the Medical Records Section of the Philippine General Hospital and the UPMNIH. A code was assigned per patient and a standard data collection form was used. The data was encoded using Microsoft Excel and access to the files was restricted to the investigator to maintain privacy and data security.

Descriptive statistics was used to summarize the clinical data obtained for this study. Qualitative data such as sex, family history, presence of intellectual disability, death, set of presenting symptoms, confirmatory testing, management, and cause of death were expressed in frequencies and proportions. The median age at presentation and median age at diagnosis together with the minimum and maximum values were reported. The estimated incidence of IMDs was calculated by dividing the number of diagnosed cases by the total number of live births during the 17 -year period and multiplying by 100,000 .

\section{RESULTS}

Over the 17 -year period covered by this review, the total number of births in the country was $29,348,063 .{ }^{4}$ Table 1 shows that there was a total of 567 patients diagnosed to have IMDs, giving a minimum estimated burden of 1.9 per 100,000 livebirths. The types of IMDs included amino acid disorders (54\%), lysosomal storage disorders (14.8\%), galactosemia (17.3\%), organic acidurias (5.1\%), adrenoleukodystrophy (3.7\%), and other disorders (cystinuria, urea cycle defects, fatty acid oxidation disorders, mitochondrial respiratory chain disorders, Lowe syndrome, Lesch-Nyhan syndrome, and Menkes disease).

The five most common inherited metabolic diseases were (1) maple syrup urine disease, (2) galactosemia, (3) hyperphenylalaninemia (including classical phenylketonuria, mild hyperphenylalaninemia, and pterin defects), (4) mucopolysaccharidoses, and (5) adrenoleukodystrophy. The frequencies of these diseases are summarized in Table 2.

Two hundred thirty (230) medical records of patients diagnosed with the five most common inherited metabolic diseases were available for review. A total of 93 patients were diagnosed with maple syrup urine disease (MSUD), 42 with galactosemia, 48 with hyperphenylalaninemia (including classical phenylketonuria, mild hyperphenylalaninemia, and pterin defects), 38 with mucopolysaccharidoses, and 9 with $\mathrm{X}$-linked adrenoleukodystrophy.

\section{Maple Syrup Urine Disease}

Maple syrup urine disease (MSUD) was the most common inherited metabolic disease in the metabolic registry. Twenty-seven percent $(27.2 \%)$ had a positive family history. The median age at presentation was 7 days, with poor feeding as the most common (38/79) presenting symptom found in patients. The median age at diagnosis was 11.5 days, and the mean leucine levels on diagnosis was $1633.4 \mu \mathrm{mol} / \mathrm{L}$ (reference value: $<300 \mu \mathrm{mol} / \mathrm{L})$. Almost all patients $(84 / 86)$ were given enteral MSUD formula. Valine and isoleucine supplements became available in 2014 when the expanded newborn screening (ENBS) program started, and 11 patients received these supplements during the acute metabolic crisis. More than half of the patients (47/86) underwent peritoneal dialysis during the acute neonatal period. Developmental delay or intellectual disability was noted in $80.6 \%(58 / 72)$ of the patients on follow-up. Mortality was $50.5 \%$, with the following indicated causes of death: septic shock, disseminated intravascular coagulation, respiratory distress or failure, and dehydration. The clinical profile of maple syrup urine disease patients is summarized in Table 3.

\section{Galactosemia}

Forty-two (42) medical records of patients diagnosed with galactosemia were reviewed. Among these, 17 were diagnosed with classical galactosemia and 25 were diagnosed with non-classical galactosemia. Four percent (4\%) had a 
Table 1. Metabolic Registry, Institute of Human Genetics, UPM-NIH, from 1999-2016

\section{Disorder}

\# of Cases

Amino acid disorders 306

Maple Syrup Urine Disease

179

Hyperphenylalaninemia

62

Phenylketonuria

26

Hyperphenylalaninemia

6 Pyruvoyltetrahydropterin Synthase Deficiency

Tyrosinemia I

Non Ketotic Hyperglycinemia

Homocystinuria

Lysosomal storage disorders

Mucopolysaccharidosis (MPS)

MPS Type I

MPS Type II

MPS Type III-B

MPS Type IV

MPS Type VI

Unclassified

Gaucher Disease

Pompe

Fabry Disease

Mucolipidosis

LSD - Multiple Sulfatase Deficiency

Ceroid Lipofuscinosis Neuronal 2

Tay Sach's Disease

Niemann pick

Galactosemia

Classical

Non-classical

Organic aciduria

Methyl Malonic Aciduria (MMA)

Glutaric Aciduria Type I

Multiple Carboxylase Deficiency (MCD)

L-2-Hydroxyglutaric Aciduria

3-Methylcrotonyl-CoA carboxylase deficiency (3MCC)

\begin{tabular}{lc}
\hline Adrenoleukodystrophy (ALD) & 21 \\
\hline Heterozygous Cystinuria & 9 \\
\hline Homozygous Cystinuria & 3 \\
\hline Urea Cycle Defects & 8 \\
ArgininosuccinateLyase Deficiency Syndrome (ASALD) & 1 \\
Ornithine Transcarbamylase (OTC) Deficiency & 1 \\
Carbamoyl Phosphate Synthase (CPS) Deficiency & 6 \\
\hline Fatty acid oxidation disorders & 3 \\
Very long chain acyl CoA dehydrogenase deficiency & 2 \\
(VLCADD) & \\
Medium chain acyl CoA dehydrogenase deficiency & 1 \\
(MCAD) & 3 \\
\hline Mitochondrial respiratory chain disorders & 2 \\
MELAS & 1 \\
Respiratory Chain Complex/deficiency & 1 \\
\hline Lowe Syndrome & 1 \\
\hline Lesch Nyhan Disease & 1 \\
\hline Menkes & 567 \\
\hline Total & \\
\hline
\end{tabular}

Table 2. Types and Numbers of Inherited Metabolic Disorders diagnosed from 1999 to 2016

\section{Disorder}

Frequency (\%)

Maple Syrup Urine Disease

179 (31.6)

Galactosemia

98 (17.3)

Hyperphenylalaninemia (including classical PKU, mild hyperphenylalaninemia, and pterin defects)

62 (10.9)

Mucopolysaccharidoses

$60(10.6)$

Adrenoleukodystrophy

21 (3.7)

Others

$147(25.9)$

Total

567

Table 3. Clinical Profile of Maple Syrup Urine Disease Patients $(n=93)$

\begin{tabular}{|c|c|c|}
\hline Patient characteristic & $\mathbf{N}$ & $\begin{array}{l}\text { Frequency (\%); } \\
\text { Median (Range) }\end{array}$ \\
\hline Age at Presentation (days) & 78 & $7(0-60)$ \\
\hline Sex & 93 & \\
\hline Male & & $47(50.5)$ \\
\hline Female & & $46(49.5)$ \\
\hline Male to Female Ratio & & 1.02 \\
\hline Family History & 81 & $22(27.2)$ \\
\hline Presenting symptoms (\%) & 79 & \\
\hline Poor feeding & & $38(48.1)$ \\
\hline Lethargy & & $30(40)$ \\
\hline Positive NBS & & $12(15.2)$ \\
\hline Irritability & & $11(13.9)$ \\
\hline Seizures & & 9 (11.3) \\
\hline Sepsis-like symptoms & & $6(7.6)$ \\
\hline Sweet smell in urine & & $3(3.8)$ \\
\hline Age at Diagnosis (days) & 86 & $11.5(2-1485)$ \\
\hline $\begin{array}{l}\text { Confirmatory testing } \\
\text { Biochemical }\end{array}$ & 91 & \\
\hline 1. NBS/eNBS & & $88(96.7)$ \\
\hline 2. Plasma amino acids & & $12(13.2)$ \\
\hline Gene Testing & & $4(4.4)$ \\
\hline Urine metabolic screen & & $4(4.4)$ \\
\hline Mean Leu on diagnosis ( $\mu \mathrm{mol} / \mathrm{L})$ & 81 & $1633.4(350-4600)$ \\
\hline Management & 86 & \\
\hline Enteral MSUD formula & & $84(97.7)$ \\
\hline IV dextrose & & 68 (79.1) \\
\hline Peritoneal dialysis (acute neonatal period) & & $47(54.7)$ \\
\hline Supplements & & $11(12.8)$ \\
\hline Subspecialty Referrals & & $75(87.2)$ \\
\hline $\begin{array}{l}\text { Developmental delay or Intellectual } \\
\text { Disability }(n, \%)\end{array}$ & 72 & $58(80.6)$ \\
\hline Mortality & 93 & $47(50.5)$ \\
\hline Cause of death & 47 & \\
\hline Septic shock & & $8(17.0)$ \\
\hline Respiratory distress or failure & & $3(6.4)$ \\
\hline Disseminated intravascular coagulation & & $1(2.1)$ \\
\hline Dehydration & & $1(2.1)$ \\
\hline Not indicated & & $34(72.3)$ \\
\hline
\end{tabular}

positive family history. The median age at presentation was 10 days with positive NBS as the most common presentation (31/40). None of the patients reviewed had liver failure as the presenting symptom. The mean galactose metabolite on diagnosis was $5.0 \mathrm{mmol} / \mathrm{L}$ for classical galactosemia and $4.1 \mathrm{mmol} / \mathrm{L}$ for non-classical galactosemia (reference value: 
Table 4. Clinical Profile of Galactosemia Patients $(n=42)$

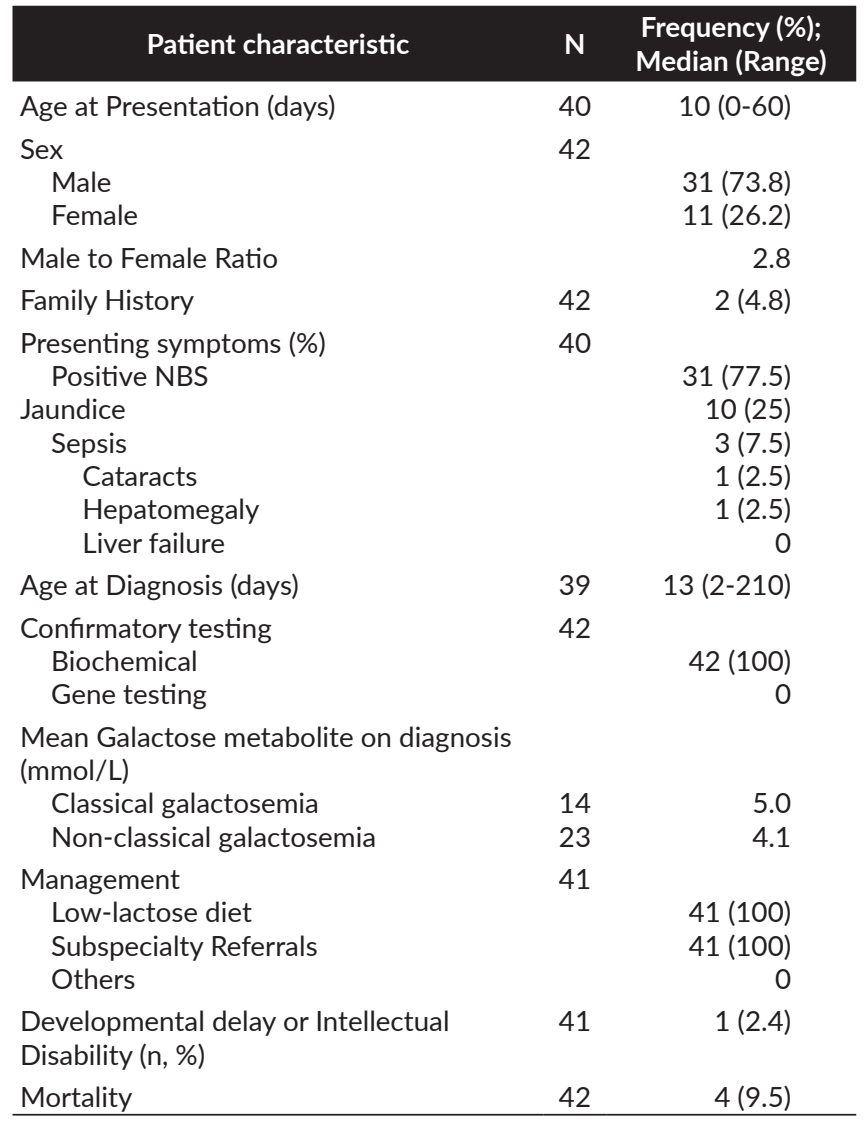

$<1.5 \mathrm{mmol} / \mathrm{L})$. All patients were managed with low-lactose diet. One patient with classical galactosemia had intellectual disability. Mortality was $9.5 \%$ (4/42), and all were cases of non-classical galactosemia. The cause of death was not indicated in the medical records reviewed. The clinical profile of galactosemia patients is summarized in Table 4.

\section{Hyperphenylalaninemia}

Forty-eight (48) medical records of patients who were diagnosed with hyperphenylalaninemia were reviewed. Sixteen (16) were diagnosed with classical phenylketonuria, 24 had hyperphenylalaninemia, and 8 had 6-pyruvoyltetrahydropterin synthase (6-PTPS) deficiency. There was a positive family history in $12.8 \%$. The median age at presentation was 9 days, with positive newborn screening as the most common presenting symptom (44/48). Biochemical testing done in the patients was as follows: BH4 loading (31/46), DHPR (46/46), and urine pterins (44/46). None underwent enzyme activity testing. Four (4) patients underwent gene testing. The mean phenylalanine level on diagnosis was $678.6 \mu \mathrm{mol} / \mathrm{L}$ (reference value: $<180 \mu \mathrm{mol} / \mathrm{L}$ ). All patients with phenylketonuria were given enteral phenylalanine-free formula, while the 8 patients with 6-PTPS deficiency were given pharmacological management. Developmental delay or intellectual disability was noted in 9 (20\%), 6 of whom had 6-PTPS deficiency (6 of 8 patients), 2 had classical PKU
Table 5. Clinical Profile of Hyperphenylalaninemia Patients (including classical phenylketonuria, mild hyperphenylalaninemia, and pterin defects) $(n=48)$

\begin{tabular}{|c|c|c|}
\hline Patient characteristic & $\mathbf{N}$ & $\begin{array}{l}\text { Frequency (\%); } \\
\text { Median (Range) }\end{array}$ \\
\hline Age at Presentation (days) & 48 & $9(0-730)$ \\
\hline Sex & 48 & \\
\hline Male & & $22(45.8)$ \\
\hline Female & & $26(54.2)$ \\
\hline Male to Female Ratio & & 0.8 \\
\hline Family History & 47 & $6(12.8)$ \\
\hline Presenting symptoms (\%) & 48 & \\
\hline Positive NBS & & $44(91.7)$ \\
\hline Neurological impairments & & $3(6.3)$ \\
\hline Intellectual disability & & $2(4.2)$ \\
\hline Age at Diagnosis (days) & 48 & $15.5(1-730)$ \\
\hline $\begin{array}{l}\text { Confirmatory testing } \\
\text { Biochemical }\end{array}$ & 46 & \\
\hline BH4 loading & & $31(67.4)$ \\
\hline DHPR & & $46(100.0)$ \\
\hline Urine pterins & & $44(95.7)$ \\
\hline Enzyme activity & & 0 \\
\hline Gene testing & & $4(8.7)$ \\
\hline Mean Phe on diagnosis ( $\mu \mathrm{mol} / \mathrm{L})$ & 47 & $693.02(148.53-3000)$ \\
\hline Management & 47 & \\
\hline Enteral PKU formula & & $16(34.0)$ \\
\hline Pharmacological treatment & & 8 (17.0) \\
\hline Subspecialty Referrals & & $31(66.0)$ \\
\hline $\begin{array}{l}\text { Developmental delay or Intellectual } \\
\text { Disability }(\mathrm{n}, \%)\end{array}$ & 45 & $9(20.0)$ \\
\hline Mortality & 48 & $1(2.1)$ \\
\hline
\end{tabular}

( 2 of 14 patients), and 1 had hyperphenylalaninemia ( 1 of 23 patients). One patient with 6-PTPS deficiency has died and the cause of death was not indicated. The clinical profile of hyperphenylalaninemia patients is summarized in Table 5 .

\section{Mucopolysaccharidosis}

Thirty-eight (38) medical records of patients diagnosed with mucopolysaccharidosis were reviewed. There was 1 patient with Mucopolysaccharidosis Type I (Hurler Syndrome), 32 with Mucopolysaccharidosis Type II (Hunter Syndrome), 1 with Mucopolysaccharidosis Type III, 3 with Mucopolysaccharidosis Type IV, and 1 with Mucopolysaccharidosis Type VI. Family history was positive in $50 \%$. The median age at presentation was 2 years old with dysmorphic features as the most common presenting symptom (17/36). The median age at confirmation of diagnosis was 6.5 years old. Urine glycosaminoglycans (GAGs) and enzyme activity confirmed the diagnosis in 37 patients, and 1 patient had gene-testing results. All patients were referred to subspecialty services. Nine (9) underwent surgery, and 3 used respiratory devices. Nine of the patients (1 patient with MPS I, and 8 patients with MPS II) had enzyme replacement therapy. None had bone marrow transplantation. Developmental delay or intellectual disability was noted in 94.7\% of the patients. Mortality was 21\% (7 patients with MPS II and 1 patient with MPS IV) with respiratory 
Table 6. Clinical Profile of Mucopolysaccharidoses Patients $(n=38)$

\begin{tabular}{|c|c|c|}
\hline Patient characteristic & $\mathbf{N}$ & $\begin{array}{l}\text { Frequency (\%); } \\
\text { Median (Range) }\end{array}$ \\
\hline Age at Presentation (years) & 36 & $2(0.08-7)$ \\
\hline $\begin{array}{l}\text { Sex } \\
\text { Male } \\
\text { Female }\end{array}$ & 38 & $\begin{array}{r}33(86.8) \\
5(13.2)\end{array}$ \\
\hline Male to Female Ratio & & 6.6 \\
\hline Family History & 38 & $19(50)$ \\
\hline $\begin{array}{l}\text { Presenting symptoms (\%) } \\
\text { Dysmorphic features } \\
\text { Developmental Delay } \\
\text { Hernia } \\
\text { Recurrent infections } \\
\text { Increasing head circumference } \\
\text { Noisy breathing } \\
\text { Difficulty in walking } \\
\text { Bone dysplasia } \\
\text { Learning difficulties } \\
\text { Behavioral disturbance }\end{array}$ & 36 & $\begin{array}{r}17(47.2) \\
7(19.4) \\
5(13.9) \\
4(11.1) \\
2(5.6) \\
2(5.6) \\
2(5.6) \\
1(2.8) \\
0 \\
0\end{array}$ \\
\hline Age at Diagnosis (years) & 38 & $6.5(1-14)$ \\
\hline $\begin{array}{l}\text { Confirmatory testing, } \\
\text { Biochemical (Urine GAGs) } \\
\text { Enzyme activity } \\
\text { Gene testing }\end{array}$ & 37 & $\begin{array}{r}37(100) \\
37(100) \\
1(2.7)\end{array}$ \\
\hline $\begin{array}{l}\text { Management } \\
\text { Enzyme replacement } \\
\text { Surgery (tracheostomy, gastrostomy) } \\
\text { Respiratory devices } \\
\text { Bone Marrow Transplantation } \\
\text { Subspecialty Referrals } \\
\text { Others }\end{array}$ & 38 & $\begin{array}{r}9(23.7) \\
9(23.7) \\
3(7.9) \\
0 \\
38(100) \\
0\end{array}$ \\
\hline $\begin{array}{l}\text { Developmental delay or Intellectual } \\
\text { Disability }(n, \%)\end{array}$ & 38 & $36(94.7)$ \\
\hline Mortality & 37 & $8(21.6)$ \\
\hline $\begin{array}{l}\text { Cause of Death } \\
\text { Respiratory failure } \\
\text { Pneumonia } \\
\text { Unspecified }\end{array}$ & 8 & $\begin{array}{r}1(12.5) \\
1(12.5) \\
6(75)\end{array}$ \\
\hline
\end{tabular}

failure and pneumonia as the indicated causes of death. The clinical profile of mucopolysaccharidoses patients is summarized in Table 6.

\section{X-linked Adrenoleukodystrophy}

Nine (9) medical records of patients diagnosed with X-linked adrenoleukodystrophy were reviewed. Six (6) patients presented with signs and symptoms of adrenoleukodystrophy and 3 were screened based on the family history. Family history was positive in $77.8 \%$. The median age at presentation among the patients was 8.5 years old, and all presented with neurological symptoms (blurring of vision, hearing loss, changes in gait, seizures). The median age at confirmation of diagnosis was 10 years old. Plasma very long chain fatty acids (VLCFA) assay was done for all patients. Intellectual disability was reported in 2 patients and the rest were not assessed. Seven (7) of the patients died and no data was available for the 2 female
Table 7. Clinical Profile of of Adrenoleukodystrophy Patients $(n=9)$

\begin{tabular}{|c|c|c|}
\hline Patient characteristic & $\mathbf{N}$ & $\begin{array}{l}\text { Frequency (\%); } \\
\text { Median (Range) }\end{array}$ \\
\hline Age at Presentation (years) & 6 & $8.5(6-10)$ \\
\hline $\begin{array}{l}\text { Sex } \\
\text { Male } \\
\text { Female }\end{array}$ & 9 & $\begin{array}{l}7(77.8) \\
2(22.2)\end{array}$ \\
\hline Male to Female Ratio & & 3.5 \\
\hline Family History & 9 & $7(77.8)$ \\
\hline $\begin{array}{l}\text { Presenting symptoms, } \\
\text { Neurological manifestations } \\
\text { Adrenal insufficiency } \\
\text { Others } \\
\quad \text { Screening }\end{array}$ & 9 & $\begin{array}{r}6(66.7) \\
0\end{array}$ \\
\hline Age at Diagnosis (years) & 9 & $10(6-61)$ \\
\hline $\begin{array}{l}\text { Confirmatory testing } \\
\text { Biochemical (VLCFA) } \\
\text { Gene testing (ABCD1) } \\
\text { Neuroimaging }\end{array}$ & 9 & $\begin{array}{l}9(100) \\
1(11.1) \\
6(66.7)\end{array}$ \\
\hline $\begin{array}{l}\text { Management } \\
\text { Corticosteroids } \\
\text { Lorenzo's oil } \\
\text { Subspecialty Referrals } \\
\text { Others (ex. hematopoietic stem cell } \\
\text { transplantation) }\end{array}$ & 9 & $\begin{array}{r}0 \\
0 \\
9(100) \\
0\end{array}$ \\
\hline Intellectual Disability & 2 & $2(100)$ \\
\hline Mortality & 7 & $7(100)$ \\
\hline
\end{tabular}

carriers. The clinical profile of adrenoleukodystrophy patients is summarized in Table 7.

\section{DISCUSSION}

Review of the registry showed the diversity of IMDs diagnosed in the country. The overall exact incidence and prevalence of inherited metabolic diseases in the Philippines is unknown and the numbers presented are probably an underestimate. The clinical presentations of the patients with the five most common IMDs were similar to those reported in literature..$^{5-10}$

Maple syrup urine disease (MSUD) was the most common amino acid disorder and the most common IMD in this review. It is caused by defects in the branchedchain $\alpha$-ketoacid dehydrogenase complex, which results in elevations of the branched-chain amino acids in plasma, $\alpha$-ketoacids in urine, and production of alloisoleucine. It is amenable to treatment through dietary restriction of branched-chain amino acids and outcomes are generally good if it is detected and treated within the first few days of life. ${ }^{5}$ The worldwide prevalence of MSUD is 1:185,000 while the local prevalence based on the Newborn Screening Reference Center (NSRC) data is 1:71,347.11,12 This may be due to a founder mutation reported in the Filipino population wherein a novel deletion creating a new terminal exon of the dihydrolipoyl transacylase (DBT) gene was found in 8 out of 13 families. ${ }^{13}$ Twenty-two patients (27.2\%) reviewed in 
this study had a family history of MSUD, which highlights the importance of counseling the parents regarding the recurrence risk of this autosomal recessive condition. One of the challenges in the management of children with MSUD is late diagnosis. In this review, the median age of presentation was 7 days while the median age of diagnosis was 11 days. This was beyond the golden period for the initiation of treatment before irreversible neurologic damage occurs which is between 7-10 days of life. ${ }^{14}$ The presenting signs and symptoms were non-specific (e.g. lethargy, poor feeding, and irritability), contributing to a low index of suspicion among clinicians especially those who may not be familiar with the disease. Despite the inclusion in the newborn screening program, the problem of delayed diagnosis and management persisted, possibly because of geographical factors and physical distance or difficulty in transportation and delivery of newborn screening cards. ${ }^{14}$ Delayed diagnosis may be responsible for the complications with more than half of the patients in this review requiring peritoneal dialysis during the management of the acute crisis. Despite being a treatable disease, more than $80 \%$ of the patients were diagnosed with developmental delay or intellectual disability, and half of the patients in this review eventually expired. Aside from late diagnosis, poor metabolic control is seen to be an important risk factor for developmental delay and death. ${ }^{14}$

Galactosemia was the second most common inherited metabolic disease in the registry with a local prevalence of 1:79,332 for combined classical and non-classical galactosemia cases based on the Newborn Screening Reference Center (NSRC) data. ${ }^{11}$ In a previous study involving 4 unrelated Filipino patients with classical galactosemia, mutational analysis of the galactose-1-phosphate uridyltransferase (GALT) gene showed 4 missense mutations wherein 2 have been previously reported while 2 were novel mutations, suggesting that GALT mutations are ethnic-specific and that galactosemia is a heterogeneous disorder at the molecular level. ${ }^{15}$ The patients with galactosemia in this review had a generally good prognosis, with less than $10 \%$ mortality and only one patient with intellectual disability. Diagnosis by newborn screening has allowed the prevention of acute complications with the timely institution of appropriate management. Patients with non-classical galactosemia have a better long-term outcome compared to patients with classical galactosemia as the only complication associated are bilateral cataracts. ${ }^{6,16}$ However, in this review, the 4 cases of mortality were patients with non-classical galactosemia. No cause of death was indicated but all 4 were diagnosed late (60 to 210 days old). Late diagnosis may have contributed to these outcomes or there may be other causes of death unrelated to galactosemia.

Hyperphenylalaninemia was the third most common inherited metabolic disease in the registry with a local prevalence of 1:121,143 based on Newborn Screening Reference Center (NSRC) data. ${ }^{11}$ Hyperphenylalaninemia can result from phenylalanine hydroxylase (PAH) deficiency or defects in the synthesis or recycling of tetrahydrobiopterin (BH4), an obligate co-factor for the PAH enzyme. Mutation analysis of the phenylalanine hydroxylase $(P A H)$ gene done on 4 unrelated Filipino patients with elevated phenylalanine on newborn screening (2 with PKU, 2 with tetrahydrobiopterin deficiency) showed 4 previously known mutations and confirmed the heterogeneity of mutations at the PAH locus in Filipinos. ${ }^{17}$ Defects in either PAH or the synthesis or recycling of $\mathrm{BH} 4$ results in accumulation of phenylalanine, as well as deficiency in tyrosine, L-dopa, dopamine, melanin, catecholamines, and 5-hydroxytryptophan. ${ }^{8}$ Developmental delay or intellectual disability was noted in $9(20 \%)$ of the patients in this review, and majority were cases of 6-PTPS deficiency. The patient who expired was a case of 6-PTPS deficiency diagnosed at 1 year 9 months old presenting with spasticity at 2 months old. The neurologic symptoms of 6-PTPS deficiency are due to neurotransmitter deficiency secondary to the deficiency of the co-factor $\mathrm{BH} 4$, an obligate co-factor for tyrosine hydroxylase and tryptophan hydroxylase in the production of dopamine and serotonin, respectively. ${ }^{18}$ Early and continuous treatment has been shown to prevent intellectual disability and improve outcomes in patients with PAH deficiency and 6-PTPS deficiency. ${ }^{8,19}$ Patients with mild hyperphenylalaninemia are not at risk for developing significant intellectual, neurologic, and neuropsychologic deficits or abnormalities of the white matter. ${ }^{20}$ In this review, there was one patient with mild hyperphenylalaninemia who had intellectual disability. This may indicate that specific cognitive functions are affected by even modest elevations of phenylalanine or it may be due to other factors such as dietary intake, genotype, or psychosocial factors that might influence neurocognitive outcomes. ${ }^{21}$ Hence, early screening for hyperphenylalaninemia and subsequent testing to rule out BH4 synthesis/recycling defects is important to improve neurocognitive outcomes.

Mucopolysaccharidoses (MPS) are a group of disorders involving defects of the enzymes that are involved in the lysosomal degradation of the mucopolysaccharides (glycosaminoglycans), which lead to chronic, progressive, and multisystemic disorders. In this review, the most common was MPS II (32/38), which is similar to east Asian countries. ${ }^{22}$ All the 19 patients who had a positive family history in this review were cases of MPS II. There was note of delay in the confirmation of diagnosis since MPSs have generally nonspecific signs and symptoms. At present, hematopoietic stem cell transplant (HSCT) and enzyme replacement therapy (ERT) are effective treatments for some MPSs as they can improve the patient's clinical status and quality of life. ${ }^{23}$ However, the cost of ERT is prohibitive and is not covered by the national health insurance. Thus, most of the patients are on supportive management at present. In this review, almost all the patients had intellectual disability and a quarter eventually expired. In all cases of MPS, except for a few mild cases, the disease is ultimately fatal with an average life expectancy of one to two decades, if left untreated. ${ }^{24}$ 
Adrenoleukodystrophy (ALD) is an X-linked condition characterized by impaired peroxisomal beta-oxidation of very long-chain fatty acids (VLCFA; $\geq \mathrm{C} 22$ ), with consequent accumulation of VLCFA in plasma and all tissues, including the white matter of the brain, the spinal cord, and the adrenal cortex. It is the most common peroxisomal disorder with an estimated birth incidence of 1:17,000 newborns. In affected males, there are 3 types: Addisononly, cerebral ALD, (childhood, adolescent and adult), and adrenomyeloneuropathy. Female carriers are usually asymptomatic but may develop adrenomyeloneuropathylike symptoms. ${ }^{25}$ Plasma VLCFA levels were elevated in all the patients in this review. A recent local study showed a diagnostic yield of 54\% among patients suspected to have the disease and among carriers. ${ }^{26}$ Early recognition and confirmation of diagnosis are important because the benefits of allogenic hematopoietic stem cell transplant (HSCT), the present treatment of choice, such as arresting the progression of demyelination, will be achieved when the procedure is done at the early stage of the disease. ${ }^{25}$ Being an X-linked condition, ALD carries a 50\% recurrence risk for males and a $50 \%$ carrier risk for females, hence immediate evaluation of at-risk siblings and relatives should be done following the diagnosis of the proband to identify those who can benefit from early HSCT. There are 7 institutions in the country accredited by the Department of Health (DOH) to perform HSCT, but the number of procedures done remains low due to the prohibitive cost, paucity of physicians trained in blood and marrow transplantation, and lack of suitable donors for many patients. ${ }^{27,28}$

The presence of rare diseases such as IMDs in the country warrants attention from the national health care administration. Majority of the patients with IMDs, especially diseases that are not included in the newborn screening, were diagnosed late leading to preventable developmental delay or intellectual disability and death. IMDs may not be a top priority in the national health programs, but it is pertinent to note that these inheritable diseases affect Filipinos and contribute to significant morbidity and mortality, which has significant impact not only on the families but also on society. Developmental delay and intellectual disability often result in psychological, social, and economic burdens, and IMDs are an important cause of treatable developmental delay and intellectual disability. ${ }^{29}$ Advances in the understanding of IMDs have led to significant progress in the discovery of effective treatments such as dietary modulation of enzymatic precursors to reduce toxic metabolites, drugs that enhance disposal of toxic metabolites, enzyme replacement therapy, substrate reduction therapy, and novel compounds with direct pathway effects. ${ }^{30}$ Early identification and treatment have been successful in limiting the impact of developmental disabilities, complications, and death. ${ }^{31} \mathrm{~A}$ long-term strategic plan should be put into place to address these diseases. The National Rare Disease Act was passed in March 2016 (Republic Act No. 10747, 2016) and it specified the formulation of a comprehensive and sustainable health system for orphan or rare disorders such as IMDs. The expedited implementation is anticipated to help improve the access to care and improve the overall quality of life of these patients, enabling them to be more productive members of society.

\section{CONCLUSION}

This study highlights the diversity of IMDs present in the country and an overview of the outcomes of the patients diagnosed with IMDs based on the NIH - IHG Metabolic Registry from 1999 to 2016. The implementation of the newborn screening program has improved the diagnosis of some IMDs, but outcomes may still be improved by reducing the delays in diagnosis and by giving the necessary management through better access to the current standards of treatment. The full implementation of the National Rare Disease Act is foreseen to improve access to comprehensive healthcare and overall quality of life of patients with IMDs in the country.

\section{Statement of Authorship}

All the authors participated in preparing, writing, and submitting the manuscript. MRF performed majority of the data collection and data analysis. MDC edited the manuscript. All authors read and approved the final manuscript.

\section{Author Disclosure}

All authors declared no conflicts of interest.

\section{Funding Source}

This research did not receive any specific grant from any funding agency.

\section{REFERENCES}

1. Alfadhel M, Beanmeakel M, Hossain M, Mutairi F, Othaim A, Alfares A, et al. Thirteen year retrospective review of the spectrum of inborn errors of metabolism presenting in a tertiary center in Saudi Arabia. Orphanet J Rare Dis. 2016; 11:126.

2. Tan I, Gajra B, Lim M. Study of inherited metabolic disorders in Singapore - 13 years experience. Ann Acad Med Singapore. 2006; 35(11):804-13.

3. Padilla C, Cutiongco-De La Paz E. Genetics and genomic medicine in the Philippines. Mol Genet Genomic Med. 2016; 4(5):494-503.

4. Philippine Statistics Authority: Birth statistics [Internet]. 2017 [cited 2018 May]. Available from: https://psa.gov.ph/tags/birth-statistics.

5. Blackburn P, Gass J, Vairo F, Farnham K, Atwal H, Macklin S, et al. Maple syrup urine disease: mechanisms and management. App Clin Genet. 2017; 10:57-66.

6. Berry G. Classic Galactosemia and clinical variant galactosemia [Internet]. [cited 2018 Apr]. Available from: https://www.ncbi.nlm. nih.gov/books/NBK1518.

7. Bosch AM, Bakker HD, van Gennip AH, van Kempen JV, Wanders RJ, Wijburg FA. Clinical features of galactokinase deficiency: a review of the literature. J Inherit Metab Dis. 2002; 25(8):629-34.

8. Burgard P, Lachmann R, Walter J. Hyperphenylalaninenaemia. In: Saudubray JM, Baumgartner M, Walter J, eds. Inborn Metabolic 
Diseases: Diagnosis and Treatment. 6th edition. Berlin: Springer, 2016. pp. 251-263.

9. Jones S, Wijburg F. Mucopolysaccharidoses, Oligosaccharidoses and Sialic Acid Disorders. In: Saudubray JM, Baumgartner M, Walter J, eds. Inborn Metabolic Diseases: Diagnosis and Treatment. 6th edition. Berlin: Springer, 2016. pp. 577-590.

10. Raymond G, Moser A, Fraterni A. X-linked adrenoleukodystrophy [Internet]. [cited 2018 May]. Available from https://www.ncbi.nlm. nih.gov/books/NBK1315/

11. Newborn Screening Reference Center: Prevalence of disorders among Filipino newborns (1996-2016) [Internet]. [cited 2017 Sep]. Available from https://newbornscreening.ph/images/stories/ ResourcesPrevalence/prevalence-2016.pdf.

12. Chiong M, Tan M, Cordero C, Fodra E, Manliguis J, Lopez C, et al. Plasma amino acid and urine organic acid profiles of Filipino patients with maple syrup urine disease (MSUD) and correlation with their neurologic features. Mol Genet Metab Rep. 2016; 9:46-53.

13. Silao C, Padilla C,Matsuo M. A novel deletion creating a new terminal exon of the dihydrolipoyl trans-acylase gene is a founder mutation of Filipino maple syrup urine disease. Mol Genet Metab. 2004; 81(2):100-4.

14. Hamoy L, Chiong M, Estrada S, Cordero C. Challenges in the management of patients with maple syrup urine disease diagnosed by newborn screening in a developing country. J Community Genet. 2017; 8(1):9-15.

15. Estrada S, Canson D, Silao C. Mutational analysis of the GALT gene in Filipino patients. Kobe J Med Sci. 2013; 59(3): E106-11.

16. Hennerman J, Schadewaldt P, Vetter B, Shin Y, Mönch E, Klein J. Features and outcome of galactokinase deficiency in children diagnosed by newborn screening. J Inherit Metab Dis. 2011; 34(2):399-407.

17. Silao C, Canson D, Hernandez K, Chiong M, Estrada S, Padilla C. Mutations of the phenylalanine hydroxylase (PAH) gene in Filipino patients with phenylketonuria. Acta Med Philipp. 2009; 43(2):36-9.

18. De Dios J, Chiong M. Two Filipino patients with 6-pyruvoyltetrahydropterin synthase deficiency. Acta Med Philipp. 2009; 43(2):18-21.

19. Vockley J, Anderson H, Antshel K, Braverman N, Burton B, Frazier D, et al. Phenylalanine hydroxylase deficiency: Diagnosis and management guideline. Genet Med. 2014; 16(2):188-200.

20. Weglage J, Piesch M, Feldman R, Koch HG, Zschocke J, Hoffmann $\mathrm{G}$, et al. Normal clinical outcome in untreated subjects with mild hyperphenylalaninemia. Pediatr Res. 2001; 49(4): 532-6.
21. de la Parra A, Garcia M, Waisbren S, Cornejo V, Raimann E. Cognitive functioning in mild hyperphenylalaninemia. Mol Genet Metab Rep. 2015; 5:72-5.

22. Khan S, Peracha H, Ballhausen D, Wiesbauer A, Rohrbach M, Gautschi M, et al. Epidemiology of mucopolysaccharidoses. Mol Genet Metab. 2017; 121(3):227-40.

23. Scarpa M, Orchard P, Schulz A, Dickson P, Haskins M, Escolar $\mathrm{M}$, et al. Treatment of brain disease in the mucopolysaccharidoses. Mol Genet Metab 2017; 122: 25-34.

24. Tomatsu S, Fuji T, Fukushi M, Oguma T, Shimada T, Maeda M, et al. Newborn screening and diagnosis of mucopolysaccharidoses. Mol Genet Metab. 2013; 110(1-2):42-53.

25. Engelen M, Kemp S, de Visser M, van Geel B, Wanders R, Aubourg $\mathrm{P}$, et al.X-linked adrenoleukodystrophy (X-ALD): clinical presentation and guidelines for diagnosis, follow-up, and management. Orphanet J Rare Dis. 2012; 7:51.

26. Fojas E, Manliguis J, Lopez C, Decena S, Fonacier K, Chiong M. A review of the results of the very long chain fatty acid analyses for X-linked adrenoleukodystrophy at the Biochemical Genetics Laboratory of the Institute of Human Genetics-National Institutes of Health, Manila. Acta Med Philipp. 2017; 51(3):223-7.

27. Department of Health - Health Facilities and Services Regulatory Bureau Health Advisory dated 18 August 2016 [Internet]. 2016 [cited 2018 Nov]. Available from: https://www.doh.gov.ph/sites/default/files/ health_advisory/stem_cell_advisory_updated.pdf.

28. Baylon HG, Del Rosario MLU, Tiangco BJ. The status of blood and marrow transplantation in the Philippines. Bone Marrow Transplant. 2008; 42:S118-20.

29. Van Karnebeek C, Stockler S. Treatable inborn errors of metabolism causing intellectual disability: a systematic literature review. Mol Genet Metab. 2012; 105(3):368-81.

30. Vernon H. Inborn errors of metabolism: advances in diagnosis and therapy. JAMA Pediatr 2015; 169(8):778-82.

31. Powell K, Braun K, Singh R, Shapira S, Olney R, YearginAllsopp M. Prevalence of developmental disabilities and receipt of special education services among children with an inborn error of metabolism. J Pediatr. 2010; 156(3):420-6. 